\title{
BIO-PESTISIDA BERBASIS EKSTRAK TEMBAKAU DARI LIMBAH PUNTUNG ROKOK UNTUK TANAMAN TOMAT (Lycopersicum esculentum)
}

\author{
Eko Siswoyo $\left.{ }^{1, *}\right)$, Rahmah Masturah ${ }^{1}$, Nurul Fahmi ${ }^{1}$ \\ $\left.{ }^{1}\right) J u r u s a n$ Teknik Lingkungan, Fakultas Teknik Sipil dan Perencanaan, Universitas Islam \\ Indonesia (UII), Jl. Kaliurang Km 14,5 Yogyakarta 55584 Indonesia \\ e-mail: eko_siswoyo@uii.ac.id
}

\begin{abstract}
Abstrak
Keberadaan limbah puntung rokok belum dimanfaatkan dengan baik dan hingga saat ini hanya dibuang sebagai sampah. Padahal tembakau dari limbah puntung rokok ini mempunyai potensi untuk dijadikan bio-pestisida untuk kegiatan pertaian yang ramah lingkungan. Tujuan dari penelitian ini adalah untuk menganalisis kualitas dan efisiensi tembakau dari puntung rokok sebagai bio-pestisida, mengetahui residu pada tomat diukur dengan instrumen Kromatografi Spektrometer-Massa (GC-MS) dan mengetahui intensitas serangan hama melalui metode ekstraksi maserasi. Senyawa kimia diperoleh dengan membandingkan daerah puncak kromatogram untuk setiap sampel. Hasil penelitian menunjukkan bahwa senyawa Alkaloid dan Terpenoid sebagai bentuk senyawa kimia yang terkandung pada bio-pestisida. Residu biopestisida yang terdeteksi adalah asam heksadekanoat dan asam dodecanoik, kedua senyawa ini termasuk dalam asam lemak jenuh. Intensitas serangan hama pada tanaman tomat dengan penggunaan biopestisida pada tanaman yang terserang ulat adalah sebesar $21 \%$ termasuk dalam kategori sedang. Sedangkan untuk intensitas serangan hama pada tanaman tanpa penggunaan biopestisida adalah sebesar $69 \%$ dan termasuk dalam kategori serangan hama puso (paling berat). Hasil ini menunjukkan bahwa limbah puntung rokok mempunyai potensi yang cukup baik untuk dijadikan bio-pestisida menggantikan petisida yang ada di pasaran.
\end{abstract}

Kata kunci: Bio-pestisida; puntung rokok; tanaman tomat; tembakau

\begin{abstract}
The presence of litter of cigarette butts is still not utilized and just disposed as a waste, eventhough tabaco, the main material of the waste, has a potential as a bio-pesticide for agricultural activity. The purpose of the curret study were to analyse the efficiency and competitiveness of the tobacco quality from cigarette butts that might be used as bio-pesticide. This research also obtains the relative levels of residues on washed tomatoes (Lycopersicum esculentum) plant measured by Gas Chromatography-Mass Spectrometry (GC-MS) and aims the attack pest intensity. Maceration extraction method was utilized during this study in order to extract tabaco into bio-pesticide. Relative chemical compound measured by comparing the peak area of the chromatograms for each sample. The results showed that relatively Alkaloid and Terpenoid compounds as the form of chemical compounds. Residues hexadecanoic acid and dodecanoic acid are found by GC-MS instrument and both compounds are saturated fatty acid. The attack pest intensity of the organisms was detected for $21 \%$ that was in medium level that used bio-pesticide. Sides, the attack pest intensity for non bio-pesticide plant was $69 \%$ and detected as high level. The findings suggested that tabaco from cigarette butts has a potencial as bio-pesticide instead of commercial pesticide.
\end{abstract}

Keywords: Bio-pesticide; cigarette butts; tobacco; tomatoes 


\section{Pendahuluan}

Pestisida adalah salah satu substansi yang digunakan untuk membunuh atau mengendalikan berbagai hama dalam proses produksi pertanian. Sebagian besar pestisida merupakan bahan kimia sintetik dengan penggolongan berdasarkan bahan aktif seperti Amamektin benzoate. Bahan aktif ini merupakan golongan amidin yang digunakan sebagai salah satu pembasmi hama jenis insektisida. Namun penggunaan pestisida sintetis dalam jangka panjang dapat menggangu kesehatan manusia karena banyaknya kandungan zat kimia yang bersifat karsinogenik. Salah satu dampak penggunaan pestisida yaitu mengakibatkan menurunnya tingkat kekebalan tubuh (Corsini et al., 2013) serta menurunkan kualitas sperma (Perry and Martenies and Perry, 2013). Selain itu juga dapat mengakibatkan berbagai penyakit lain seperti kangker, Parkinson dan beberapa kelainan lain (Gilden et al., 2010). Oleh karena itu, penggunaan pestisida nabati atau botanik yang bersifat alamiah merupakan salah satu alternatif yang perlu dipertimbangkan. Sejak pertama kali dirintis oleh Champbell dan Sulivan pada tahun 1993, hingga kini banyak penelitian yang menguatkan bahwa bahan tanaman tertentu memiliki zat beracun untuk membasmi hama pada penelitian. Total produksi biopestisida dunia adalah lebih dari 3.000 ton/tahun. Petani india baru memanfaatkan 2,5\% kebutuhan biopestisida dari pasar pestisida (Gupta and Dikshit, 2010).

Dalam penerapan di bidang pertanian, ternyata tidak semua pestisida mengenai sasaran. Kurang lebih hanya 20 persen pestisida mengenai sasaran sedangkan 80 persen lainnya jatuh ke tanah. Akumulasi residu pestisida tersebut mengakibatkan pencemaran lahan pertanian. Apabila masuk ke dalam rantai makanan, sifat beracun bahan pestisida dapat menimbulkan berbagai penyakit seperti kanker, mutasi, bayi lahir cacat, CAIDS (Chemically Acquired Deficiency Syndrom) dan sebagainya (Sa'id, 1994). Maka dari itu penggunaan pestisida sintetis sangat berbahaya jika tidak sesuai dengan kaidah pengguaannya, sehingga dibutuhkan alternatif lain seperti pestisida nabati atau biopestisida agar penggunaan pestisida sintetis dapat dikurangi. Beberapa peneliti telah mengembangkan bio-pestisida dari berbagai bahan, seperti bahan propagule aktif jamur (Suwahyono dan wahyudi, 2008).

Produksi rokok yang sangat tinggi di Indonesia ditambah dengan besarnya jumlah perokok yang pada tahun 2015 mencapai $34,5 \%$ dari penduduk Indonesia atau setara dengan 80 juta jiwa (Santoso, 2016). Hal ini berpotensi pada meningkatnya timbulan sampah puntung rokok yang harus dikelola. Hingga saat ini puntung rokok masih menjadi sampah yang sering menimbulkan masalah dan belum dimanfaatkan dengan baik. Padahal puntung rokok ini yang sebagian besar komponennya adalah tembakau mempunyai potensi untuk dijadikan biopestisida untuk kegiatan pertanian. Kadar nikotin dalam puntung rokok yang dapat dijadikan sebagai bahan insektisida (Aji et al., 2015).

Dalam penelitian ini akan dilakukan ekstraksi tembakau dari bahan limbah puntung rokok untuk dijadikan bio-pestisida untuk budidaya tanaman tomat. Senyawasenyawa kimia yang ada dalam bio-pestisida serta dalam tanaman tomat tersebut akan diuji dengan menggunakan instrumen GCMS.

\section{Metode Penelitian}

\section{Persiapan Bahan}

Puntung rokok yang telah dikumpulkan sebanyak $1 \mathrm{Kg}$, diambil tembakaunya kemudian dihaluskan dengan menggunakan blender lalu diayak menggunakan saringan 40 mesh hingga diperoleh bubuk tembakau. Didapatkan 250 gram tembakau puntung rokok untuk mendapatkan bubuk tembakau sesuai dengan ukuran saringan 40 mesh.

\section{Ekstraksi Maserasi}

Pengambilan ekstrak tembakau sebagai biopestisida dilakukan dengan proses ekstraksi maserasi kemudian dilanjutkan dengan evaporasi. Ekstraksi dilakukan menggunakan wadah tabung kaca. Tembakau yang telah dihaluskan dan diayak dimasukkan ke dalam wadah kaca, kemudian ditambahkan dengan pelarut etanol absolute sebanyak $500 \mathrm{~mL}$. Proses maserasi dilakukan selama 120 jam. Larutan ekstrak yang diperoleh selanjutnya diuapkan untuk memisahkan pelarut dan ekstraknya menggunakan alat rotary evaporator.

\section{Perlakuan Bio-pestida}

Perlakuan biopestisida pada tanaman Tomat dikelompokkan menjadi 3 yaitu sebagai kontrol dengan tidak menggunakan pestisida, menggunakan pestisida sintetis dan dengan biopestisida. Masing - masing mendapatkan perlakuan terdiri dari 5 tanaman Tomat. Penanaman ditargetkan berlangsung selama 45 hari. 


\section{Uji Rendemen}

Pengujian uji rendemen dilakukan untuk mengetahui persentase ekstrak nikotin dari 1 $\mathrm{kg}$ puntung rokok yang menghasilkan 250 gram tembakau dengan ekstraksi maserasi. Rendemen ekstrak dihitung dengan rumus mengikuti (Drastinawati dan Rozanna, S.I., 2013).

$\%$ Rendemen $=\frac{\text { Bobot Ekstrak } \text { yang didapat }}{\text { Bobot Serbuk di Ekstraksi }} \times 100 \%$

Uji efektivitas biopestisida dilakukan untuk mengetahui pengaruh dari bio pestisida terhadap tanaman Tomat. Pengujian efektivitas dari biopestisida dilakukan dengan cara menghitung intensitas serangan hama. Rumus yang digunakan untuk menghitung intensitas serangan hama mengikuti (Manopo et al., 2012).

$$
\mathrm{I}=\frac{\mathrm{n}}{\mathrm{N}} \times 100 \%
$$

Keteragan:

I = Intensitas Serangan (\%)

$\mathrm{n}=$ Jumlah Tanaman yang Terserang Hama $\mathrm{N}=$ Jumlah Tanaman yang Diamati

\section{Uji Residu}

Uji residu dilakukan untuk mengetahui apakah masih terdapat residu pestisida di dalam buah Tomat, serta faktor apa saja yang mempengaruhi keberadaan residu tersebut pada tanaman Tomat yang menggunakan pestisida sintetik, biopestisida, dan tanpa pestisida. Metode uji residu pestisida dimodifikasi dari Fennol et al., (2007) dengan menggunakan alat Gas ChromatographyMass Spectrometri (GC-MS) yang dapat mendeteksi komponen atau senyawa dalam sampel. Sebelum melakukan pengujian menggunakan GC-MS dilakukan prosedur preparasi sampel yang akan diuji. Preparasi sampel dilakukan dengan cara: Tomat yang telah dipanen kemudian dicuci dan ditimbang sebanyak $10 \mathrm{gram}$. Dimasukkan kedalam blender ditambahkan $100 \mathrm{~mL}$ campuran aseton-n heksa $(5: 95 \mathrm{v} / \mathrm{v})$ selanjutnya dilumatkan selama 2-3 menit. Kemudian disaring melalui corong yang telah diberi saringan glass woll ditampung dalam labu ukur $200 \mathrm{~mL}$. Blender dan corong dibilas 3 kali, setiap kali dengan n-heksan dan dicampur dengan hasil saringan, kemudian ditambah n-heksan sampai batas tanda. Sejumlah $200 \mathrm{~mL}$ saringan di pekatkan dengan rotary evaporator sehingga volume menjadi $2 \mathrm{~mL}$.

Larutan hasil yang telah dipekatkan dengan rotary evaporator pada suhu $60^{\circ} \mathrm{C}$. Kemudian disuntikkan sejumlah $1 \mu$ l kedalam kromatografi gas dengan kondisi pengukuran pada GC-MS diatur sebagai berikut : suhu injeksi : $250{ }^{\circ} \mathrm{C}$, mode injeksi : splits, mode kontrol aliran : tekanan, tekanan : 78,2 $\mathrm{kPa}$, aliran total : $23,4 \mathrm{~mL} / \mathrm{min}$, aliran kolom : 0,97 $\mathrm{mL} / \mathrm{min}$, kecepatan linier : $37,0 \mathrm{~cm} / \mathrm{min}$, pembacaan MS : $0-39,5$ min

\section{Hasil dan Pembahasan}

Nilai rendemen ekstrak tembakau dengan menggunakan ethanol absolute (99\%) dimana hasil ekstraksi diperoleh sebanyak 29,37 gr dengan $250 \mathrm{gr}$ rendaman dari $1 \mathrm{~kg}$ puntung rokok ini diperoleh nilai rendaman adalah $11,7 \%$. Besar kecilnya nilai rendaman menunjukkan efektifitas pada proses ekstraksi. Efektifitas ekstraksi dipengaruhi oleh jenis pelarut yang digunakan, ukuran partikel simplisia, metode dan lamanya ekstraksi. Adapun persentase rendaman yang diperoleh dari hasil remaserasi adalah sebesar 15,4\%. Berdasarkan kedua perhitungan diatas dapat diketahui persentase rendaman pada saat maserasi dan remaserasi memiliki selisih 3,7\% lebih tinggi dari rendemen awal. Hal ini menunjukkan tingkat efektivitas yang berkurang terhadap penggunaan biopestisida jika digunakan berulang-ulang. Penggunaan pelarut etanol pada proses ekstraksi maserasi ini karena sifatnya yang mampu melarutkan hampir semua zat, baik yang bersifat polar, semi polar, dan non polar (Arifin et al., 2006).

Hasil pengujian mengenai besarnya hasil rendaman ekstrak tembakau dan jenis senyawa-senyawa kimia yang ada dalam biopestisida dapat dilihat pada Tabel 1 dan Tabel 2. Terlihat bahwa terdapat dua senyawa yang terkandung di dalam ekstrak tembakau. Senyawa yang paling mendominasi adalah senyawa Piridin (C10H14N2) yang tergolong dalam senyawa Alkaloid. Piridin merupakan alkaloid yang dapat digunakan sebagai insektisida. Senyawa alkaloid mempunyai sifat basa yang mengandung satu atau lebih atom nitrogen dan biasanya berupa sistem siklis. Alkaloid mengandung atom karbon, hidrogen, nitrogen dan pada umumnya mengandung oksigen dan merupakan hasil metabolisme dari tumbuh-tumbuhan. Adapun senyawa yang terdeteksi lainnya adalah senyawa Neopitadin (C2H38). Senyawa ini termasuk jenis senyawa Terpenoid. Senyawa Terpenoid 
biasanya terkandung senyawa hidrokarbon dan hidrokarbon teroksigenasi.

Tabel 1. Hasil ekstraksi tembakau

\begin{tabular}{|c|c|c|c|c|}
\hline \multicolumn{2}{|c|}{$\begin{array}{l}\text { Serbuk } \\
\text { tembakau } \\
\text { (g) }\end{array}$} & \multicolumn{2}{|c|}{$\begin{array}{c}\text { Bobot Ekstrak Hasil } \\
\text { Ekstraksi }(\mathrm{g})\end{array}$} & \multirow{2}{*}{\begin{tabular}{l}
\multicolumn{1}{c}{$\begin{array}{c}\text { Nilai } \\
\text { Rendem } \\
\text { en (\%) }\end{array}$} \\
Remaser \\
asi
\end{tabular}} \\
\hline & $\begin{array}{l}\text { Masera } \\
\text { si }\end{array}$ & $\begin{array}{l}\text { Remaser } \\
\text { asi }\end{array}$ & $\begin{array}{l}\text { Maser } \\
\text { asi }\end{array}$ & \\
\hline 250 & 29,37 & 38,8 & 11,74 & 15,52 \\
\hline
\end{tabular}

Tabel 2. Senyawa pada ekstrak biopestisida

\begin{tabular}{ccccc} 
Peak & $\begin{array}{c}\text { Waktu } \\
\text { retensi } \\
\text { (menit) }\end{array}$ & $\begin{array}{c}\text { Area } \\
(\%)\end{array}$ & $\begin{array}{c}\text { Senyawa } \\
\text { dugaan }\end{array}$ & $\begin{array}{c}\text { Golongan } \\
\text { senyawa }\end{array}$ \\
5 & 10,51 & 43,2 & $\begin{array}{c}\text { Piridin } \\
\text { (Pyridine) } \\
\text { Piridin }\end{array}$ & Alkaloid \\
6 & 10,67 & 40,3 & Alkaloid \\
8 & 16,38 & 3,1 & $\begin{array}{c}\text { (Pyridine) } \\
\text { Neopitadin } \\
\text { (Neophytadi } \\
\text { ene) }\end{array}$ & Terpenoid \\
\hline & & & \\
\hline
\end{tabular}

Hasil pengujian mengenai jenis senyawa yang terdapat pada tanaman tomat sebagaimana terlihat pada Tabel 3 menunjukkan bahwa senyawa Hexadecanoic acid dan Dodecanoic acid ditemukan dalam tanaman tomat yang diuji. Kedua senyawa tersebut masuk dalam golongan senyawa asam lemak jenuh.

Tabel 3. Senyawa pada ekstrak tomat

\begin{tabular}{ccccc}
\hline Peak & $\begin{array}{c}\text { Waktu } \\
\text { retensi } \\
\text { (menit) }\end{array}$ & $\begin{array}{c}\text { Area } \\
(\%)\end{array}$ & $\begin{array}{c}\text { Senyawa } \\
\text { dugaan }\end{array}$ & $\begin{array}{c}\text { Golong } \\
\text { an } \\
\text { senya } \\
\text { wa }\end{array}$ \\
\hline 16 & 28,10 & 6,26 & $\begin{array}{c}\text { Hexadecanoic } \\
\text { acid }\end{array}$ & $\begin{array}{c}\text { Asam } \\
\text { lemak } \\
\text { jenuh }\end{array}$ \\
17 & 28,34 & 15,02 & $\begin{array}{c}\text { Dodecanoic } \\
\text { acid } \\
\text { Asam } \\
\text { lemak } \\
\text { jenuh } \\
\text { Asam } \\
\text { lemak } \\
\text { jneuh }\end{array}$ \\
\hline
\end{tabular}

Pengamatan visual pengaruh pemberian biopestisida, pestisida dan kontrol dilakukan dengan mengamati kondisi daun tanaman tomat. Kondisi tanaman tomat setelah mendapatkan perlakuan tersebut dapat dilihat pada Gambar 1.

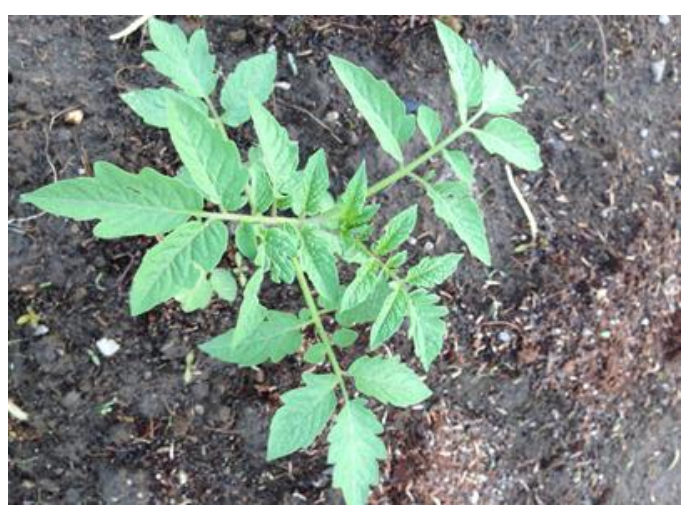

a
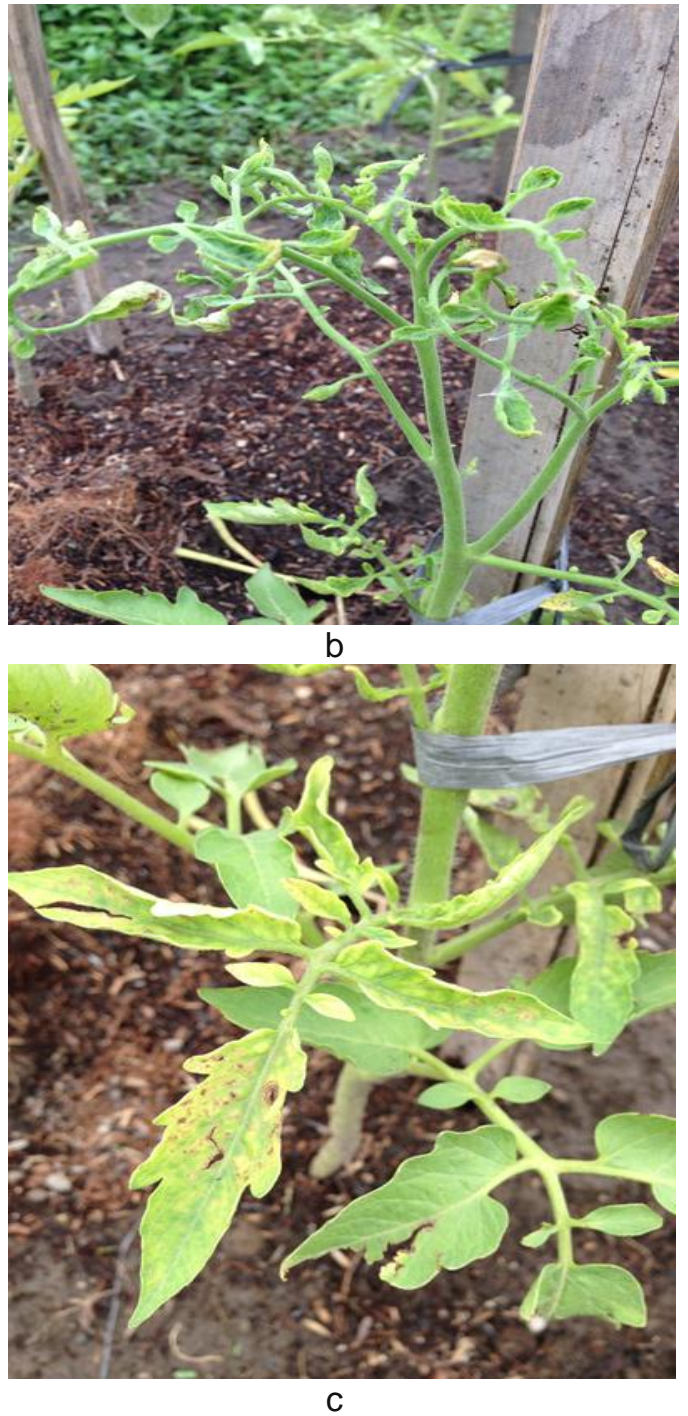

Gambar 1. Kondisi tanaman tomat a. diberi biopestisida, b. diberi pestisida kimia dan c. tanpa pestisida

Terlihat bahwa kondisi daun tanaman tomat yang disemprot bio-pestisida esktrak tembakau dari puntung rokok terlihat lebih segar dan tidak mengerut.

Pengaruh pemberian bio-pestisida terhadap pertumbuhan tanaman tanaman uji, khususya pada jumlah daun yang terserang hama dan tingkat keberhasilan panen ditunjukkan pada Tabel 4. 
Tabel 4. Pengaruh pemberian biopestisida dan pada tanaman uji

\begin{tabular}{lcccc}
\hline Perlakuan & $\begin{array}{c}\text { Jumlah } \\
\text { daun } \\
\text { normal }\end{array}$ & $\begin{array}{c}\text { Jumlah } \\
\text { daun } \\
\text { terserang } \\
\text { hama }\end{array}$ & $\begin{array}{c}\text { Sukses } \\
\text { panen }\end{array}$ & $\begin{array}{c}\text { Gagal } \\
\text { panen }\end{array}$ \\
\hline $\begin{array}{l}\text { Diberi } \\
\text { biopestisida } \\
\begin{array}{l}\text { Tanpa } \\
\text { biopestisida }\end{array}\end{array}$ & 22 & 6 & 4 & 1 \\
\hline
\end{tabular}

Intensitas serangan adalah derajat serangan organisme pembasmi tanaman (OPT) atau derajat kerusakan tanaman pangan yang disebabkan oleh OPT. Untuk menilai serangan OPT yang menyebabkan kerusakan mutlak digunakan rumus Rumus Intensitas serangan (Moekasan dan Prabaningrum, 2011) yaitu membagi jumlah tanaman atau bagian tanaman yang terserang dengan jumlah tanaman atau bagian tanaman yang tidak terserang dan terserang pada suatu tanaman. Adapun intensitas serangan hama pada tanaman tomat dengan penggunaan biopestisida pada tanaman yang terserang ulat adalah sebesar $21 \%$ Intensitas serangan hama termasuk dalam kategori sedang. Sedangkan untuk intensitas serangan hama pada tanaman tanpa penggunaan biopestisida adalah sebesar $69 \%$ sehingga termasuk dalam kategori serangan hama puso (paling berat).

Hasil ini sesuai dengan penelitian Listiyat et al., (2012) yang menyatakan bahwa kandungan bahan kimia di dalam esktrak tembakau dari limbah puntung rokok menunjukkan bioaktivitas pada serangga. Bioaktifitas ini memiliki fungsi sebagai bahan penolak (repellent), penghambat makan (antifeedant), penghambat perkembangan serangga (insect growth regulator), dan penghambat peneluran (oviposition deterrent). Biopestisida dari ekstrak tembakau puntung rokok termasuk penghambat makan (antifeedant) dan penghambat peneluran (oviposition deterrent).

\section{Kesimpulan}

Ekstraksi tembakau dari puntung rokok menghasilkan bio-pestisida yang mempunyai kemampuan untuk kegiatan pertanian. Hasil penelitian menunjukkan bahwa senyawa Alkaloid dan Terpenoid sebagai bentuk senyawa kimia yang terkandung pada biopestisida. Residu bio-pestisida yang terdeteksi adalah asam heksadekanoat dan asam dodecanoik, kedua senyawa ini termasuk dalam asam lemak jenuh. Intensitas serangan hama pada tanaman tomat dengan penggunaan biopestisida pada tanaman yang terserang ulat adalah sebesar $21 \%$ termasuk dalam kategori sedang. Sedangkan untuk intensitas serangan hama pada tanaman tanpa penggunaan biopestisida adalah sebesar $69 \%$ sehingga termasuk dalam kategori serangan hama puso (paling berat). Hasil ini menunjukkan bahwa puntung rokok mempunyai potensi untuk dijadikan biopestisida yang ramah lingkungan.

\section{Daftar Pustaka}

Aji, A., Maulinda, L., Amin, S. (2015). Isolasi nikotin dari puntung rokok sebagai insektisida. Jurnal Teknologi Kimia Unimal, 4 (1) 100-120.

Arifin, H. Nelvi, A., Dian, H., Roslinda, R. (2006). Standarisasi Ekstrak Etanol Daun Eugenia Cumini Merr.J. Sains Tek. Far 11(2). $88-92$.

Corsini, E., Sokooti, M., Galli, C.L., Moretto, A., Collosio, C. (2012). Pesticide induced immunotoxicity in humans: $A$ comprehensive review of the existing evidence. Toxicology, (307) 123135.

Drastinawati dan Rozanna, S. I. (2013). Pemanfaatan Ekstrak Nikotin Limbah Puntung Rokok sebagai Inhibitor Korosi. Jurnal Teknobiologi, IV (2) 91 - 97.

Gilden, R.C., Huffling, K., Sattler, B., (2010). Pesticides and health risks. J. Obstet. Gynecol. Neonat. Nurs. 39, 103-110.

Gupta, S. and Dikshit, A.K. (2010). Biopesticides: An eco-friendly approach for pest control; journal of Bio-pesticides $186-188$.

Listiyanti, A. Nurkalis, U. Sudiyanti., Hestiningsih R. (2012). Ekstraksi Nikotin Dari Daun Tembakau (Nicotina Tabacum) Dan Pemanfaatannya Sebag.ai Insektisida Nabati Pembunuh Aedes Sp. Jurnal ilmiah Mahasiswa, Universitas Diponegoro.

Moekasan, T.K. dan Prabaningrum, L. (2011). Budidaya Cabe merah di bawah naungan untuk menekan serangan hama dan penyakit. Yayasan Bina

Tani Sejahtera Lembang-Bandung Barat.

Manopo, R. Salaki, C. Mamahit, J. Senewe, E. (2012). Padat populasi dan intensitas serangan hama walang sangit (Leptocorisa Acuta Thunb) pada tanaman padi sawah di Kabupaten 
Minahasa Tenggara. Manado: Fakultas Pertanian Universitas Sam Ratulangi.

Mutiatikum, D. Lestari, S. P. Alegantina. (2002). Analisis residu pestisida peretrin dalam tomat dan selada dari beberapa pasar di Jakarta. Volume XII nomor 2. Media litbang kesehatan. Jakarta

Perry, M.J., Martenies, S.E. (2013). Environmental and occupational pesticide exposure and human sperm parameters: A systematic review. Toxicology, (307) 66-75.
Sa'id, E.G. (1994). Dampak Negatif Pestisida, Sebuah Catatan bagi Kita Semua. Agrotek, Vol. 2(1) 71-72.

Santoso, R. (2016). Dilema Kebijakan Pengendalian Tembakau di Indonesia. Kebijakan, 21 (3) 201-2119.

Suwahyono, U. dan Wahyudi, P. (2008). Produksi Dan Formulasi Biopestisida dari Propagul Aktif Jamur Beauveria Bassiana. J. Tek. Ling. 9 (1). 85-91. 